\title{
AN EFFICIENT HYBRID ACTIVE POWER FILTER (H-APF) FOR HARMONIC MITIGATION USING COMPENSATION TECHNIQUES
}

P. Sandhya

Associate Professor, Department of EEE, The Oxford College of Engineering, Bengaluru, (India).

E-mail: urssandhyarai@gmail.com

ORCID: https://orcid.org/0000-0003-1562-3086

Nagaraj Ramrao

Vice Chancellor, Kalasalingam Academy of Research and Education, Tamilnadu, (India).

E-mail: nagaraj.ramrao@gmail.com

ORCID: https://orcid.org/0000-0003-2542-5999

\section{Citación sugerida:}

Sandhya, P., y Ramrao, N. (2021). An efficient Hybrid Active Power Filter (H-APF) for harmonic mitigation using compensation techniques. 3C Tecnología. Glosas de innovación aplicadas a la pyme, Edición Especial, (noviembre, 2021), 623-643. https://doi.org/10.17993/3ctecno.2021.specialissue8.623-643 


\section{ABSTRACT}

The deviation of physical characteristics like current, voltage, and frequency in power systems affects the damage of electronic equipment with significant power loss. Power quality issues are resolved using filters like passive filters (PF) and active power filters (APF). The drawbacks of the PF and APF are resolved using Hybrid-APF. In this article, the HybridAPF (H-APF) is designed for harmonic reduction and power quality improvements using current compensation technique. The proposed H-APF has of $3 \Phi$ - AC Source connected in series with Non-linear load, Shunt-PF, and Shunt-APF. The Shunt-PF (S-PF) is connected in Series with Shunt-APF (S-APF) to form a Hybrid-APF. The compensation techniques include PQ-method/DQ Method and Hysteresis-Current- Controller (HCG) are used to reduce the harmonics from the Load. The complete model is designed using MATLAB Simulink and analyze the simulated voltage-current waveforms. The H-APF is compared with different filtering technique concerning THD and reactive power with improvements. The H-APF improves the THD of 5.76\% over shunt-APF using PQ-Method. The H-APF using PQ-Method improves the THD over 69.54\% than the H-APF using DQ-method.

\section{KEYWORDS}

Hybrid -APF, Active Power Filter, Passive Filter, Harmonic Filter, PQ Theory, DQ Theory, HCC, Simulink Modelling. 


\section{INTRODUCTION}

The growth and economy of the country depend on the power generation and its usage. Due to recent advancement in technology, people demand high-quality power to their daily need. The problem occurred in power system due to voltage, current, frequency variation like swell, transient, harmonics, and spikes in electrical and electronic equipment's. The usage of the new power electronic devices starts from small non-linear load in the home to extensive industrial applications. The power quality problems are resolved in recent years by incorporating new techniques in power systems (Ahsan, Pan, \& Li, 2018; Diab et al., 2018). The voltage and current harmonics in power systems are solved by using filtering methods. The harmonics are occurred by electromagnetic interference and voltage/ current distortion. The Reactors, transformations-K-factor, Pulse and Phase shifting solutions, Tuned, low-pass filters, active and hybrid-Harmonic filters are the different harmonics mitigation techniques to compensate the current from the loads (Schwanz, Bollen, \& Larsson, 2016).

The Passive Filters (PF's) are used to mitigate the current harmonics, but facing problems with parallel resonance. The APF's are used to reduce the drawbacks of PF's and mitigate the harmonics. The APF mainly performs the harmonics detection, reference current signal calculation and gate pulses generation. In general, APF is classification is processed on Topology, Converter, and Number of phases. The converter base includes voltage and current source inverter. The Topology type includes Unified Power Quality-Conditioner (UPQC), Series, Shunt, and Hybrid APF. The phases include single-phase, 2-Wire and 3-phase, 3 or 4 -wire. The Hybrid-APF are classified based on the topology includes Shunt APF with Series APF, Shunt APF with Shunt PF, APF in Series along with Shunt PF and Series APF with Shunt PF. The control strategies are used to compensate the current in APF, which includes proper signal conditioning, reference signal generation based on time and frequency domain, DC Link controlling using PI Controller, sliding mode, and Fuzzy and finally firing signal generation using HCC, PWM and other Techniques (Demirdelen et al., 2013).

Most of the existing research done is on active filters or passive filters individually. The active filters classify as the shunt filter, which is costly and not convinced for higher energy 
systems and series filters to isolate the harmonics, but not to a great extent. Similarly, passive filters eliminate particular harmonics but cause parallel resonance. The hybrid filter offers efficient and cost-effective solutions with harmonic elimination with better power quality improvements. In the proposed design Hybrid-APF is designed, is the integration of S-PF connected in Series with S-APF. The Hybrid-APF overcomes the drawbacks of the APF. The Hybrid-APF is designed using controlling strategies, which includes reference signal generation with time-domain using PQ - method and DQ-Method, DC-Link controlling using PI Controller, firing signal generation using HCC.

The proposed method has hybrid combination of Passive and Shunt active power filter, using current compensation techniques like PQ-Theory and Hysteresis current controller. The switching losses are controlled by PI controller and improve the APF computations. The proposed approach is improved version of conventional methods in terms of THD and reactive power. The proposed model is easily reconfigurable by replacing PQ-method with DQ-method and vice versa. In future, by replacing the PI controller with artificial neural network (ANN) based controller to improve the THD and power.

Section 1.1 discusses the background of the previous research works of Hybrid-APF and Shunt -APF. Section 2 describes the detailed architecture of Hybrid-APF and elaborates the current compensation techniques which include PQ-Method, DQ-Method and HCG. Section 3 explains the simulation results of the Hybrid-APF. Section 4 discuss the other filtering methods with THD and reactive power comparison with improvements and also concludes the overall work with improvements.

\subsection{THE BACKGROUND}

This section explains the background of existing APF and Hybrid-APF using different approaches. Chau (2016) present Adaptive current control technique for H-APF, which includes Prediction model, identification, and fuzzy neuro controller with a cost function. The fuzzy neuro controller is working on membership function used in the fuzzy layer and rules layer. Temerbaev and Dovgun (2014) describe the power quality in distributed systems using H-APF, which contains load compensation with Notch IIR Filter for harmonic mitigation. The analysis of Shunt H-APF Controller by Harmonic voltages, Series H-APF controlled by source harmonic current and Combined H-APF controlled 
by Load harmonic current is discussed. A practical design approach for transformer-less Shunt-APF is explained by Unnikrishnan et al. (2015) which include design procedures for selecting the components and controlling techniques. The controlling method includes PQ-Theory with Low and high Filter along with PI Controller for current and dc-voltage controlling along with THD findings for different harmonic orders. Das, Ray, and Mohanty (2017) explain the RLS algorithm for harmonic mitigation using Hybrid-power filter with better power quality, which includes shunt PF connected series with series APF. The RLS algorithm is incorporated with DQ-theory in series AF by replacing the PI Controller and HCC. The Shunt-Hybrid-APF is designed by Tahmid and Ahmad (2017) which includes 3థ-4-wire -non-linear load, along with PF, DQ method, and PLL. The PLL is used to frequency elements of Non-linear loads and generation current by HCC.

Nandankar and More (2017) present transformer-less H-APF using different inverter topologies, which includes Six-switch Two-leg, Nine-Switch and Voltage-Source Inverters. The nine-switch Two-leg inverter-based HPF achieves better THD and reactive power. Babu, Kar, and Halder (2016) and Kar and Halder (2016) analyze the H-APF using HCC for power quality, which includes PQ-Theory, HCG for current compensation, along with Fryze compensation theory. The PQ method is better THD than Fryze compensation method. Balasubramanian and Palani (2016) present Shunt H-APF using PQ Theory with current source and voltage source type non-linear load.

The APF is designed using six Transistors are connected parallel and acts as an inverter with DG voltage capacitance along with HCG and PQ method. Thuyen (2018) presents improved P-Q harmonic detection technique for H-APF using Fuzzy logic controller. The instantaneous P-Q theory is replaced by fuzzy adjustor to decreases the response time and increases overshoot time. The same author, Thuyen (2019), extends the work by introducing a new design based on Social Spider Algorithm (SSA), which supports multiobjective optimization by replacing the Fuzzy adjuster with improved THD and reactive power. Wang, Lam, and Wong (2018) present Shunt-HAPF based on Thyristor Controller LC-coupling (TCLG) to improve the cost, reliability, and power loss of the power system.

Esfahani, Hosseinian and Vahidi (2015) describes the Fuzzy based Particle Swarm Optimization (PSO) for HAPF for better PQ improvements. Damodhar and Kumar 
(2016) explain the hardware based (FPGA) Hybrid power generator for different industrial applications. Dhineshkumar and Subramani (2018) describe the Kalman filter-based $\mathrm{H}-\mathrm{APF}$ for PQ improvements with good harmonic mitigations.

\section{PROPOSED METHOD}

In this section, the proposed Hybrid-APF is designed for Power quality improvements and to mitigate the harmonics. The Hybrid-APF is an integration of S-PF connected serially with S-APF. The primary model includes Three-Phase AC Source, RL components followed by Non-linear Load along with S-PF and S-APF.

Hybrid-APF architecture is represented in Figure 1. The Three-Phase AC mains is connected with Non-linear Load and also to Shunt Passive filter (S-PF), Shunt-APF, Universal Bridge, PI Controller and HCG

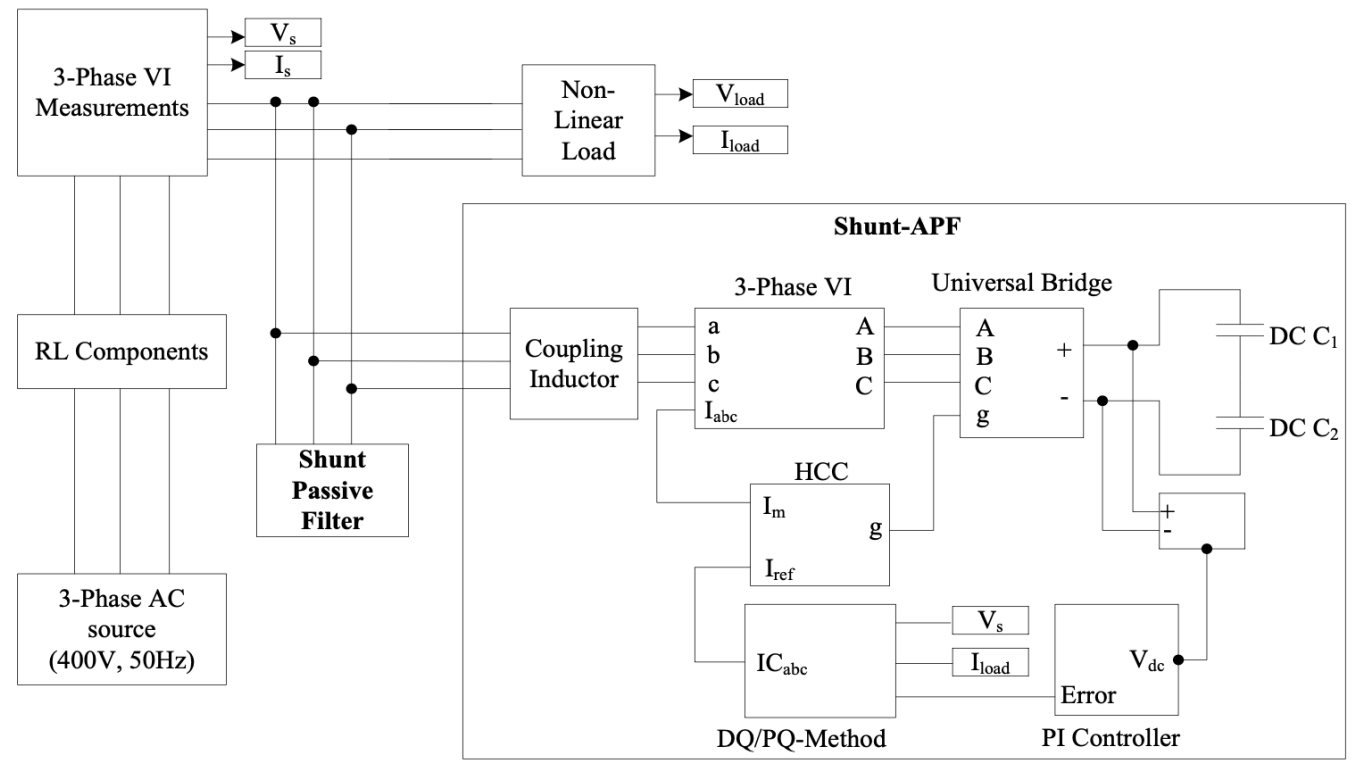

Figure 1. Detailed Architecture of Hybrid-Active Power Filter (H-APF).

Source: own elaboration.

The Non-linear load includes the 3-phase RL load, followed by six-diodes connected in parallel and an unbalanced load. The unbalanced load has three resistors $2 \Omega, 4 \Omega$ and $6 \Omega$ in parallel. The Shunt PF is wired in series with IGBT (Universal Bridge) based Shunt- 
APF to mitigate the harmonics and ended with $\mathrm{DC}$ link capacitors $\mathrm{G}_{1}$ and $\mathrm{C}_{2}$. The control strategies are incorporated to compensate the voltages and currents using PQ-Method and HCG are explained in the below section.

\subsection{PQ METHOD}

There are so many methods that are used to compensate the currents, in that PQ-method is a commonly used method in power system to improve the power quality. The instantaneous $\mathrm{I}$ and $\mathrm{V}$ waveform values are expressed by three-phase instantaneous space vectors $(\alpha \beta 0)$. These current and voltage values of the 3-phase system are converted to $\alpha \beta 0$ values with the difference of $2 \pi / 3$ on each phase. The mathematical equations are expressed in a matrix using Clark's Transformation for current and voltage conversion is below.

$$
\begin{gathered}
{\left[\begin{array}{l}
V_{a} \\
V_{\beta} \\
V_{0}
\end{array}\right]=\sqrt{\frac{2}{3}}\left[\begin{array}{crr}
1 & -1 / 2 & -1 / 2 \\
0 & \sqrt{3} / 2 & -\sqrt{3} / 2 \\
1 / \sqrt{2} & 1 / \sqrt{2} & 1 / \sqrt{2}
\end{array}\right]\left[\begin{array}{l}
V_{s a} \\
V_{s b} \\
V_{s c}
\end{array}\right]} \\
{\left[\begin{array}{l}
I_{a} \\
I_{\beta} \\
V_{0}
\end{array}\right]=\sqrt{\frac{2}{3}}\left[\begin{array}{crr}
1 & -1 / 2 & -1 / 2 \\
0 & \sqrt{3} / 2 & -\sqrt{3} / 2 \\
1 / \sqrt{2} & 1 / \sqrt{2} & 1 / \sqrt{2}
\end{array}\right]\left[\begin{array}{l}
I_{l a} \\
I_{l b} \\
I_{l c}
\end{array}\right]}
\end{gathered}
$$

The three-phase instantaneous space vectors are generated using equations (1) and (2) using $a b c$ to $a \beta 0$ or (Clark's) transformation. The zero sequence values of equations (1) and (2) are removed from the 3-phase systems, so $V_{0}$ and $I_{0}$ are not considered for further analysis. The $p$ and $q$ values are generated using below equations (3) and equation (4) are expressed in matrix form.

$$
\begin{gathered}
p=V_{\alpha} \cdot I_{\alpha}+V_{\beta} \cdot I_{\beta} \\
q=V_{\alpha} \cdot I_{\beta}-V_{\beta} \cdot I_{\alpha} \\
{\left[\begin{array}{c}
p \\
q
\end{array}\right]=\left[\begin{array}{cc}
V_{\alpha} & V_{\beta} \\
-V_{\beta} & V_{\alpha}
\end{array}\right]\left[\begin{array}{c}
I_{\alpha} \\
I_{\beta}
\end{array}\right]}
\end{gathered}
$$

The $p$ and $q$ values are compensated using average and oscillator values are expressed in the below equation (5).

$$
\begin{aligned}
& p=p_{a c}+p_{d c} \\
& q=q_{a c}+q_{d c}
\end{aligned}
$$


The $p_{a c}$ and $q_{a c}$ are oscillatory values and $p_{d c}$ and $q_{d c}$ are average values. The compensating power of $p$ and $q$ is expressed in equation (6).

$$
\begin{aligned}
& p^{*}=-p_{a c} \\
& q^{*}=-q
\end{aligned}
$$

The compensating current reference generator (CGRG) of $a \beta$ is expressed in the below equation (7).

$$
\left[\begin{array}{l}
I_{c \alpha} \\
I_{c \beta}
\end{array}\right]=\frac{1}{V_{\alpha}^{2}+V_{\beta}^{2}}\left[\begin{array}{cc}
V_{\alpha} & V_{\beta} \\
V_{\beta} & -V_{\alpha}
\end{array}\right]\left[\begin{array}{l}
p^{*} \\
q^{*}
\end{array}\right]
$$

The CCRG of $a \beta$ values are converted back to $a b c$ values using Inverse Clark's transformation and are expressed in equation (8).

$$
\left[\begin{array}{l}
I_{c a} \\
I_{c b} \\
I_{c c}
\end{array}\right]=\sqrt{\frac{2}{3}}\left[\begin{array}{cc}
1 & 0 \\
-1 / 2 & \sqrt{3} / 2 \\
-1 / 2 & -\sqrt{3} / 2
\end{array}\right]\left[\begin{array}{c}
I_{c \alpha} \\
I_{c \beta}
\end{array}\right]
$$

These $a b c$ transformed values are considered as reference current and used in Hysteresis Current Control (HCG).

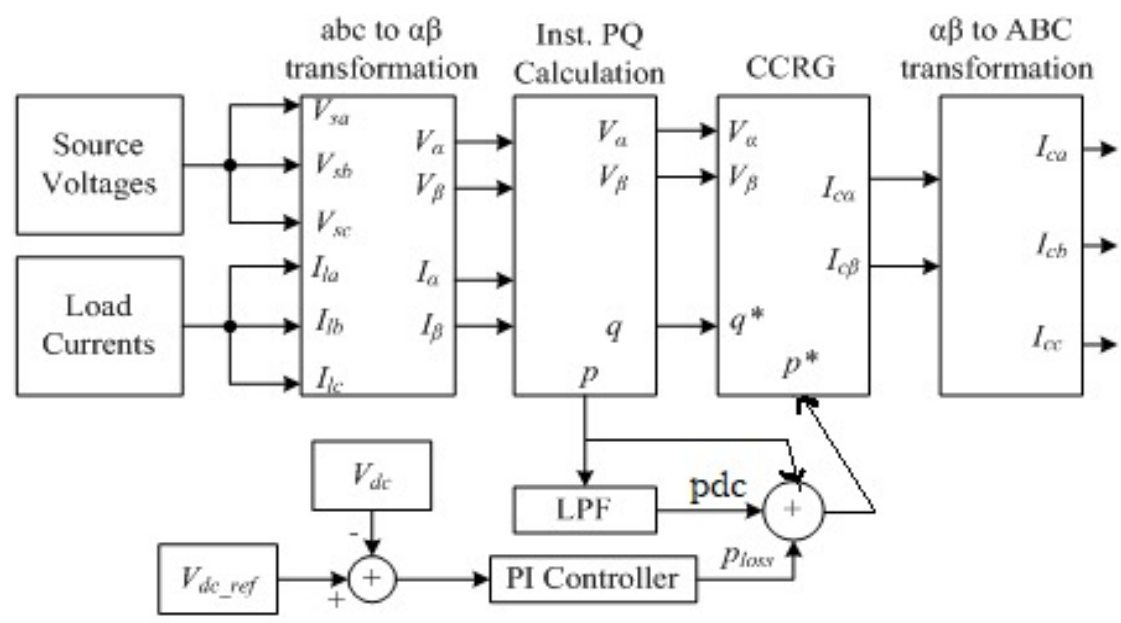

Figure 2. Current Compensation Using PQ Method.

Source: own elaboration. 
The current compensation using PQ-Method is represented in Figure 2. The 3Ф Main's voltage $\left(V_{s a b c}\right)$ and load current $\left(I_{l a b c}\right)$ from the 3-phase main power supply are given as input to the $a b c$ to $a \beta 0$ transformation block (eq (1-2)) followed by instantaneous PQ calculation using (eq (3-4)). The reference compensated current is generated by CGRG using equations (5-7). Finally, the conversion of the $a \beta$ to $\mathrm{ABC}$ transformation is achieved by equation (8).

The DC link voltage is used to improve the APF computations. PI Controller achieves the generation of the switching losses of the converters. The Hybrid-APF switching losses are balanced by using the DC link voltage as constant.

\subsection{DQ-METHOD}

The DQ-Method is similar to PQ-Method and it is represented in Figure 3. The 3-phase source voltage $\left(V_{s a b c}\right)$ is applied to Phase- Locked Loop (PLL) which is used to synchronize the different frequencies and voltage signals based on gains. The PLL output $(k)$ is used to synchronize the DQ and CGRG. The load current $\left(I_{l a b c}\right)$ is converted to $a \beta 0$ values with the difference of $2 \pi / 3$ using equation (2). The DQ calculation is achieved using park conversion below equation (9).

$$
\left[\begin{array}{l}
d \\
q
\end{array}\right]=\left[\begin{array}{cc}
\cos (k) & \sin (k) \\
-\sin (k) & \cos (k)
\end{array}\right] *\left[\begin{array}{c}
I_{\alpha} \\
I_{\beta}
\end{array}\right]
$$

The rotating reference frame $(\mathrm{RRF})-d q$ occurred based on DC components and harmonic values are frequency shifted by ' $k$ '. The DC values are extracted by using LPF with margin at the line frequency.

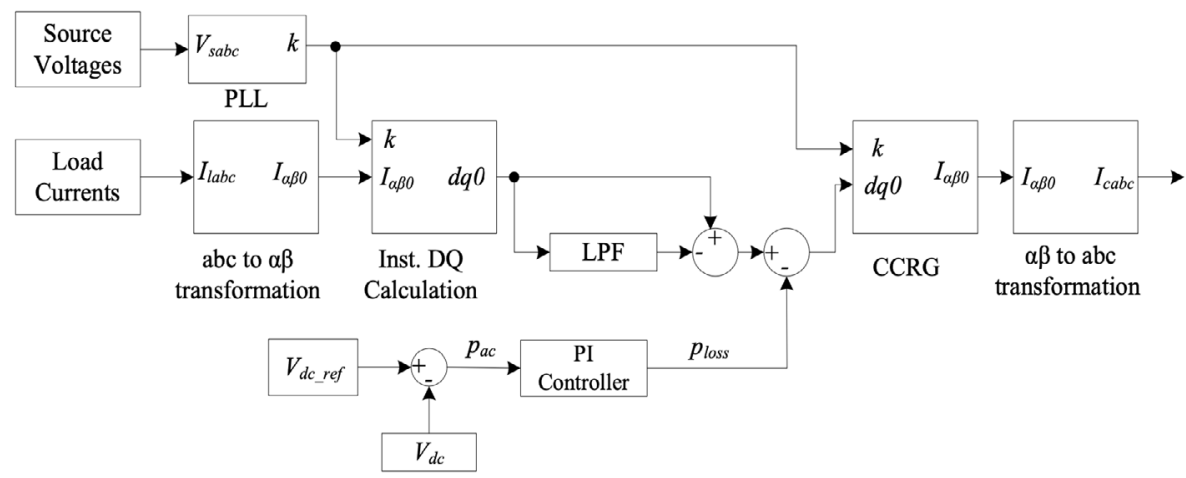

Figure 3. Current Compensation using DQ Method.

Source: own elaboration. 
The CGRG generates the $a \beta 0$ values using inverse park conversion in below equation (10).

$$
\left[\begin{array}{c}
I_{\alpha} \\
I_{\beta}
\end{array}\right]=\left[\begin{array}{cc}
\cos (k) & -\sin (k) \\
\sin (k) & \cos (k)
\end{array}\right] *\left[\begin{array}{l}
d \\
q
\end{array}\right]
$$

Apply the inverse Clarke transformation using equation (8) to generate the final compensated current $I_{c a b c}$ values and these values are processed in HCG.

\subsection{HYSTERESIS CURRENT CONTROLLER (HCC)}

The HCC is used to obtain the pulse width modulation (PWM) signals for Hybrid-APF. The HCG is working based on the feedback mechanism. The switching gate signals are given, when the error limitation crosses the given tolerance value in H-APF. The architecture of the HCG is represented in Figure4.

The PQ/DQ Method generates the compensated reference three-phase current ( $\mathrm{I}_{\text {cabc }}$ ) and measured current $\left(I_{\text {mabc }}\right)$ from the mains are inputs to the HCC model. The relation operator $(>=)$ acts as a switch to compare the three-phase reference and measured current.

If $\left(\mathrm{I}_{\mathrm{ca}}>=\mathrm{I}_{\mathrm{ma}}\right)$ then $\mathrm{g}_{1}$ will be activated (Switch $\mathrm{ON}$ ) otherwise $\mathrm{g}_{4}$ will be activated. Similarly, if $\left(I_{\mathrm{cb}}>=I_{m b}\right)$ then $g_{2}$ else $g_{5}$ gate pulses and If $\left(I_{\mathrm{cc}}>=I_{m c}\right), g_{3}$ else $g_{6}$ gate pulse is generated. The switching control of the Hybrid-APF using HCC is achieved to generates the gate pulses and input to the Universal Bridge (IGBT Inverter).

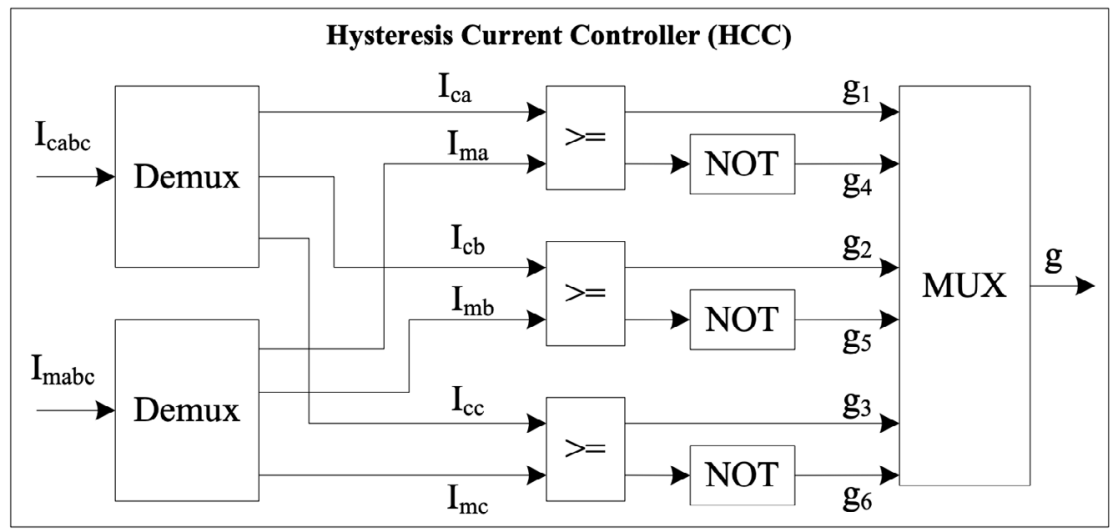

Figure 4. Block diagram of HCC.

Source: own elaboration. 


\section{RESULTS}

The Modelling of the Hybrid -APF (H-APF) is designed using Matlab-Simulink Tool and by selecting the simulation type-Discrete, Solver-Tustin, and sample period of $5 \mu \mathrm{sec}$. The $\mathrm{H}-\mathrm{APF}$ is compared with other different filtering techniques concerning Total Harmonic Distortion (THD), and reactive power (KVAR) of source voltage and current. The Modelling parameters considered as a specification for different filtering techniques are represented in Table 1.

Table 1. Specification for Different Filtering Design.

\begin{tabular}{|c|c|}
\hline DESIGN SPECIFICATIONS & VALUES \\
\hline 3-Phase AC Mains Voltage, & $400 \mathrm{~V}$ \\
\hline Fundamental Frequency & $50 \mathrm{~Hz}$ \\
\hline Line Impendence & $\mathrm{R}_{\mathrm{s}}=0.01 \Omega, \mathrm{L}_{\mathrm{s}}=1 \mu \mathrm{H}$ \\
Unbalanced Load & $2 \Omega, 4 \Omega, 6 \Omega$ \\
\hline Coupling Inductor & $1.2 \mathrm{mH}$ \\
\hline DC Capacitance (Cdc) & $\mathrm{C}_{\mathrm{dc} 1}=40 \mu \mathrm{F}, \mathrm{C}_{\mathrm{dc} 2}=40 \mu \mathrm{F}$, \\
\hline Reference DC Voltage & $\mathrm{V}_{\mathrm{dc} \_ \text {ref }}=850 \mathrm{~V}$ \\
\hline
\end{tabular}

Source: own elaboration.

The Schematic of Hybrid- Active Power Filter (H-APF) using Simulink Tool is represented in Figure 5. The $3 \Phi$ - AC source voltage $400 \mathrm{~V}$ with a frequency of $50 \mathrm{~Hz}$ is selected for different filtering techniques for harmonics reduction reactive power improvements.

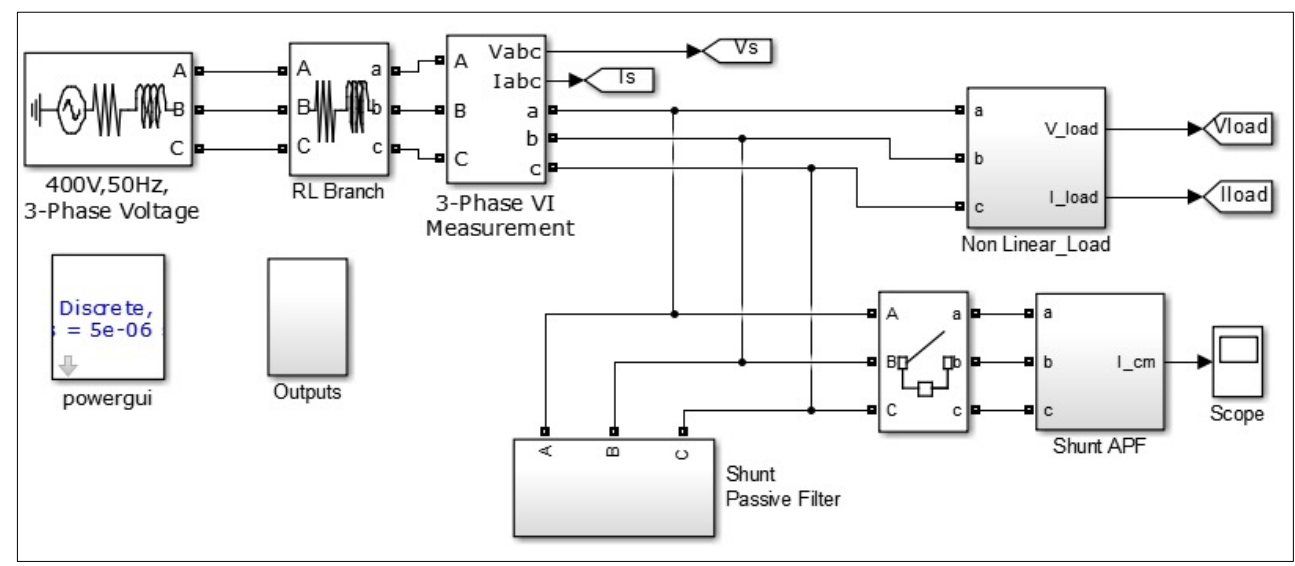

Figure 5. Schematic of Hybrid- Active Power Filter (H-APF) using Simulink Tool.

Source: own elaboration. 
To compare with Hybrid-APF, other filtering techniques are designed and analyzed in this section. The S-PF is wired to 3-phase mains, which includes three-phase RL, which is connected in parallel. Harmonic Filter is designed separately, which includes two $5^{\text {th }} \& 7^{\text {th }}$ order, $11^{\text {th }} \& 13^{\text {th }}$ order are connected in parallel. Shunt-APF is connected with 3-phase mains, which includes Universal Bride, PI Controller, followed by HCG and DQ/PQMethod.

The experimental setup is conducted for non-linear Load, Passive Filter with Load, harmonic filter with Load, Shunt-APF with Load, and proposed Hybrid-APF with load to generate the THD and reactive power results. The Hybrid-APF generates the three-phase $V_{s}, I_{s}, V_{\text {load }}$ and $I_{\text {load }}$ waveforms, after PQ method and HCC compensation technique and it is represented in Figure 6.
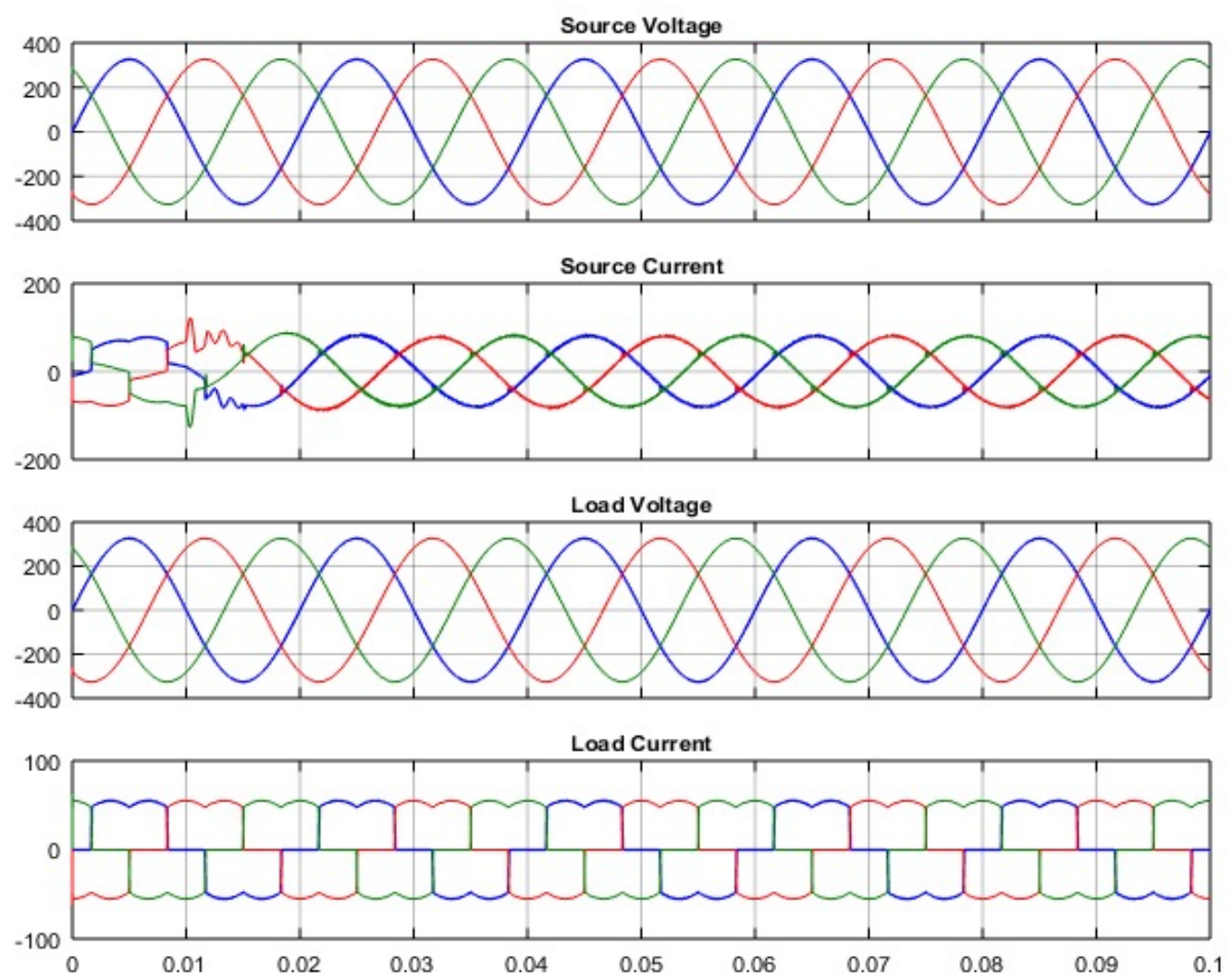

Figure 6. Hybrid -APF source and load Voltage and current waveforms Using PQ Method. Source: own elaboration. 
The Hybrid-APF has performed the current compensation using PQ method and HCC with the Load. After compensation, the DC Link V and I waveforms are represented in Figure 7 and 8, respectively.

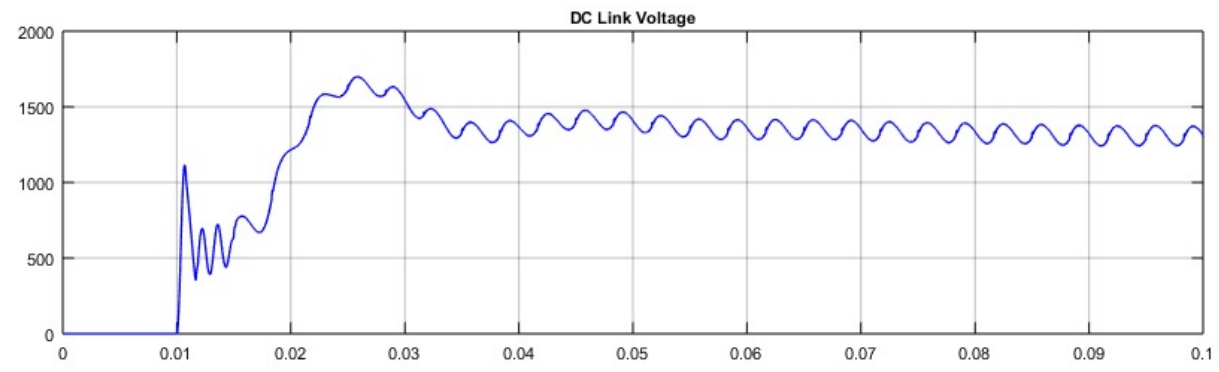

Figure 7. DC-Link Voltage Waveform after compensation.

Source: own elaboration.

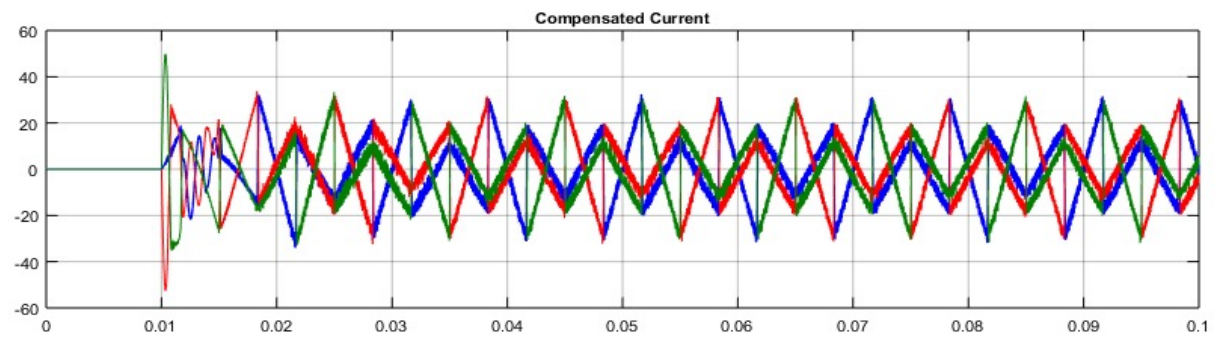

Figure 8. Compensated Current Waveform after Hybrid-APF using HCC.

Source: own elaboration.

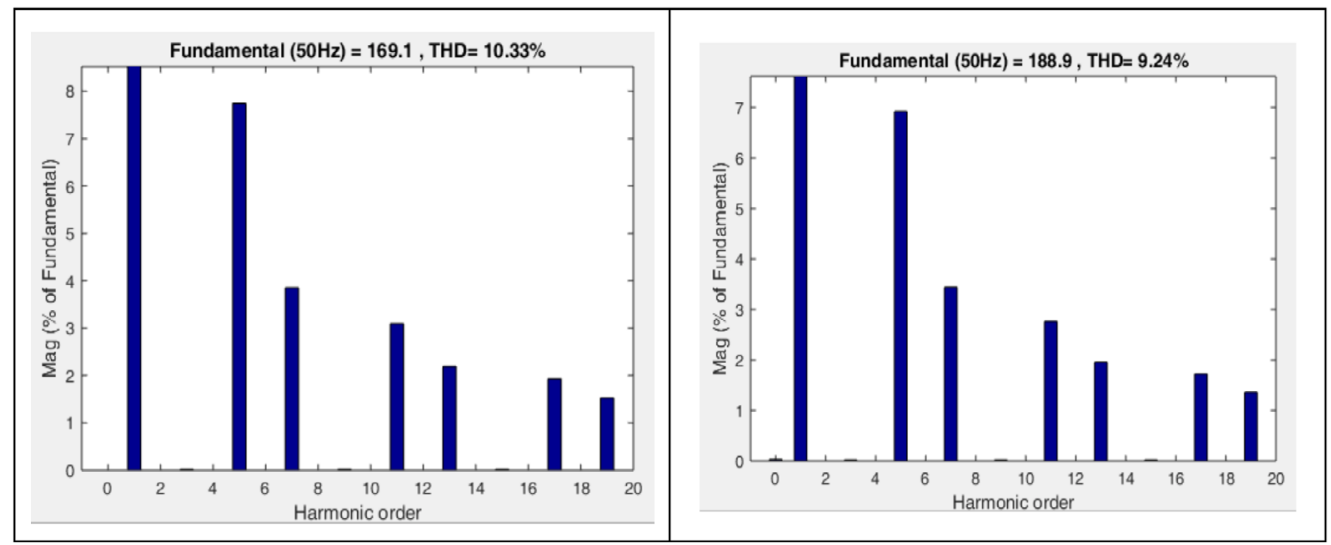




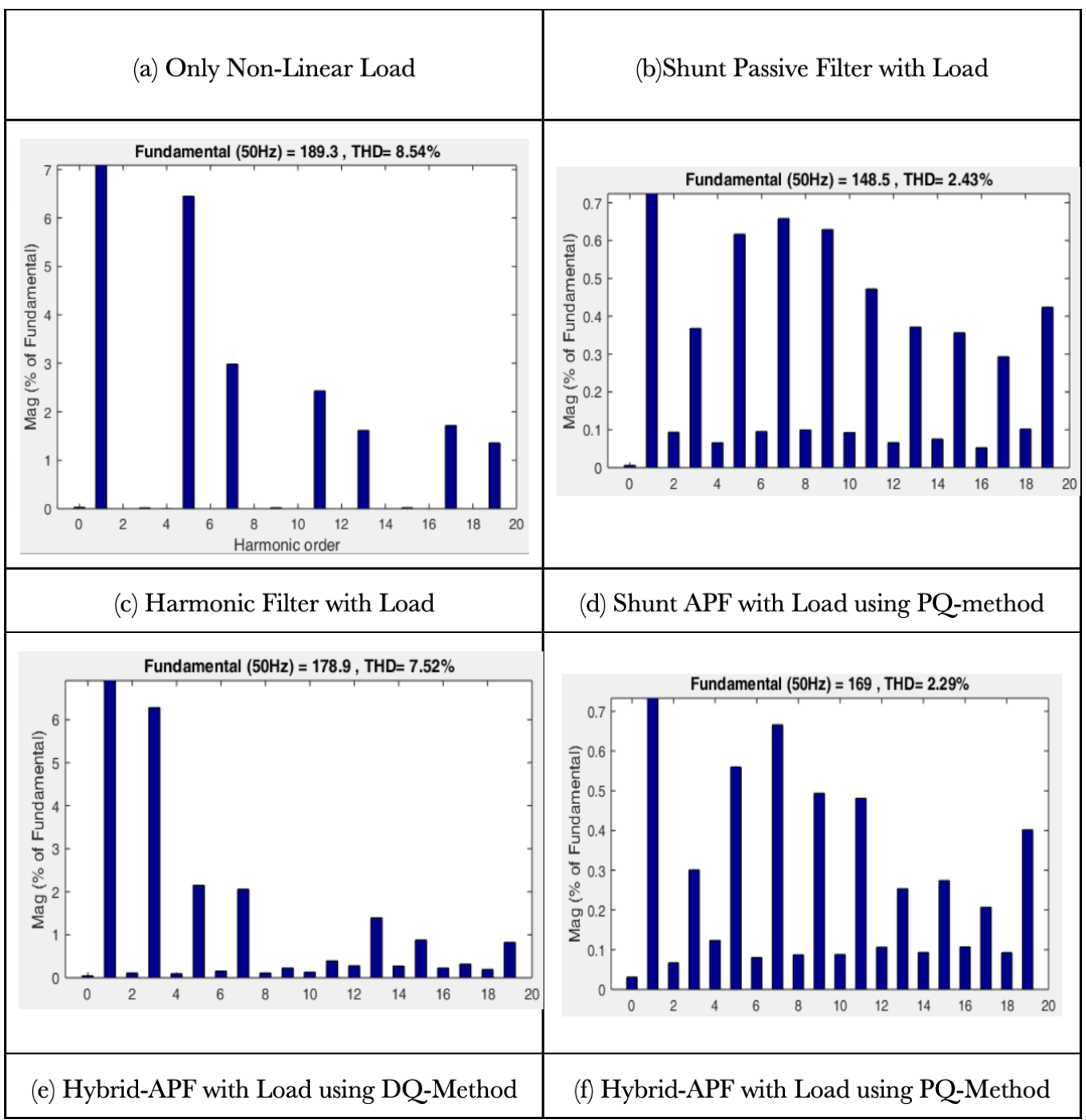

Figure 9. FFT analysis of Source Current-THD Values for Load and different Filtering techniques. Source: own elaboration.

The FFT analysis of percentage THD results are obtained after simulating the different filtering technique models with Load is represented in Figure 9. The Three- $\Phi$ source with only non-linear load results the $10.33 \%$ THD for $\mathrm{I}_{\mathrm{S}}$ before filtering technique introduced in Figure 9(a).The Shunt Passive filter with Load obtains 9.24\% THD, the Harmonic Filter with Load obtains 8.54\% THD, shunt-APF obtains the 2.43\% THD, Hybrid-APF using 
DQ-Method achieves 7.52\% and proposed Hybrid-APF using PQ-Method obtains 2.29\% THD for source current are represented in Figure 9(b-f)respectively.

\section{DISCUSSION}

The THD is a central part of the electrical modules to eliminate the harmonics in main power systems as per IEEE 519 standards. The THD calculation for H-APF using PQMethod for different Harmonics and Nonlinear loads are tabulated in Table 2 and Table 3 respectively.

Table 2. THD Calculation (\%) using different Harmonics for H-APF -PQ-Method.

\begin{tabular}{|c|c|c|c|c|c|c|}
\hline \multirow{2}{*}{ HARMONICS } & \multicolumn{3}{|c|}{ SINGLE TUNED } & \multicolumn{3}{|c|}{ DOUBLE TUNED } \\
\hline & 5 & 7 & 11 & $5 \& 7$ & $7 \& 11$ & $5 \& 11$ \\
\hline THD & 2.49 & 2.47 & 2.34 & 2.45 & 2.56 & 2.35 \\
\hline
\end{tabular}

Source: own elaboration.

Table 3. THD Calculation (\%) using different nonlinear loads for H-APF -PQ-Method.

\begin{tabular}{|c|c|c|c|c|c|c|}
\hline $\begin{array}{l}\text { NONLINEAR } \\
\text { LOADS }\end{array}$ & $R=10 \Omega$ & $R=1 K \Omega$ & $\begin{array}{c}\mathrm{RL} \\
(10 \Omega, 1 \mathrm{mH})\end{array}$ & $\begin{array}{c}R L \\
(1 \mathrm{~K} \Omega, 1 \mu \mathrm{H})\end{array}$ & $\begin{array}{c}\text { RLC } \\
(10 \Omega, 1 \mathrm{mh}, 10 \mu \mathrm{F})\end{array}$ & $\begin{array}{c}\text { RLC } \\
(1 \mathrm{~K} \Omega, 10 \mathrm{mh}, 100 \mu \mathrm{F})\end{array}$ \\
\hline THD & 2.29 & 3.07 & 2.1 & 3.05 & 3.1 & 3.13 \\
\hline
\end{tabular}

Source: own elaboration.

The THD Calculation (\%) of Vs and Is for Load and different Filtering Techniques is tabulated in Table 4. The Non-linear Load achieves $10.33 \%$ THD without filtering techniques. By using Shunt Passive Filter with Load achieves 10.55 \% THD reduction over Non-linear load model. The Harmonic Filter with Load achieves 8\% THD reduction over only Passive Filter with the Load. The Shunt-APF Filter with Load achieves 45\%THD reduction over Harmonic Filter with the Load. The Hybrid Filter with Load achieves 29.78\% THD reduction over Shunt-APF Filter with Load for source Current. The PQMethod achieves better THD 69.54\% overhead than DQ-method. 
Table 4. THD Calculation (\%) of Vs and Is for Load and different Filtering Techniques.

\begin{tabular}{|c|c|c|c|c|c|c|c|}
\hline$\%$ THD & Only Load & $\begin{array}{l}\text { Passive } \\
\text { Filter }\end{array}$ & $\begin{array}{l}\text { Harmonic } \\
\text { Filter }\end{array}$ & $\begin{array}{l}\text { Shunt-APF } \\
\text { (DQ) }\end{array}$ & $\begin{array}{l}\text { Hybrid- } \\
\text { APF (DQ) }\end{array}$ & $\begin{array}{l}\text { Shunt- } \\
\text { APF (PQ) }\end{array}$ & $\begin{array}{c}\text { Hybrid- } \\
\text { APF (PQ) }\end{array}$ \\
\hline $\begin{array}{c}\text { Source } \\
\text { Voltage }\left(\mathrm{V}_{\mathrm{s}}\right)\end{array}$ & 0.08385 & 0.08368 & 0.0796 & 0.1298 & 0.1308 & 0.2209 & 0.2094 \\
\hline $\begin{array}{c}\text { Source } \\
\text { Current }\left(I_{s}\right)\end{array}$ & 10.33 & 9.24 & 8.5 & 8.3 & 7.52 & 2.43 & 2.29 \\
\hline
\end{tabular}

The percentage of reactive power is generated for Load, and different Filtering Techniques is tabulated in Table 5. The reactive power for a non-linear load is $12.06 \%$, for Passive Filter with Load is $13.08 \%$, for Harmonic Filter with Load is $11.6 \%$, Shunt-APF with Load is $1.104 \%$ and Hybrid-APF uses $5.05 \%$ KVAR. The H-APF using DQ method utilizes $5.033 \%$ reactive power.

Table 5. Reactive Power calculation (\%) of Vs and Is for Load and different Filtering Techniques.

\begin{tabular}{|c|c|c|c|c|c|c|c|}
\hline Power & Only Load & $\begin{array}{c}\text { Passive } \\
\text { Filter }\end{array}$ & $\begin{array}{c}\text { Harmonic } \\
\text { Filter }\end{array}$ & $\begin{array}{c}\text { Shunt-APF } \\
\text { (DQ) }\end{array}$ & $\begin{array}{c}\text { Hybrid- } \\
\text { APF (DQ) }\end{array}$ & $\begin{array}{c}\text { Shunt- } \\
\text { APF (PQ) }\end{array}$ & $\begin{array}{c}\text { Hybrid- } \\
\text { APF (PQ) }\end{array}$ \\
\hline $\begin{array}{c}\text { Reactive } \\
\text { Power } \\
\text { (KVAR) }\end{array}$ & 12.06 & 13.08 & 11.6 & 1.699 & 5.033 & 1.104 & 5.05 \\
\hline
\end{tabular}

Source: own elaboration.

The Shunt-APF uses less reactive power than Hybrid-APF, but it utilizes more THD and affects for harmonics mitigation. Hybrid-APF achieves the three-Phase Current compensation for Non-linear loads.

The comparison of proposed model with similar work of Balasubramanian and Palani (2016) of same parameters with THD improvements of $34 \%$ are tabulated in Table 6. 
Table 6. Comparison of Proposed H-APF.

\begin{tabular}{|c|c|c|}
\hline PARAMETERS & PROPOSED WORK & $\begin{array}{c}\text { PREVIOUSWORK } \\
\text { (BALASUBRAMANIAN \& PALANI, 2016) }\end{array}$ \\
\hline Phase Voltage and Frequency & 230V and $50 \mathrm{HZ}$ & 230V and $50 \mathrm{HZ}$ \\
\hline Load & Full bridge Diode Rectifier & Full bridge Diode Rectifier \\
\hline Load resistance & 26 & 26 \\
\hline THD (Current) & $2.25 \%$ & $3.42 \%$ \\
\hline
\end{tabular}

Source: (Balasubramanian \& Palani, 2016).

\section{CONCLUSIONS}

This article presents the Hybrid-APF with modeling and simulation. The Hybrid-APF is an integration of Shunt-PF and Shunt-APF along with 3-Phase AC Source, RL Components and Non-linear Load. The S-APF will compensate for the voltage and currents using PQ Method and HCC. The Hybrid-APF simulation results for Source current and voltage, load current and voltage is presented. The Hybrid-APF is compared with other filtering techniques like Passive Filter, Active Harmonic Filter and Shunt-APF. The Proposed Hybrid -APF achieves better THD than other Filtering techniques. The Hybrid-APF achieves 2.29 \%THD using PQ-Method which is better than DQ-Method THD-7.52\%. The HybridAPF using PQ Method THD improvement over Shunt-APF is 5.76\%. The Hybrid-APF utilizes less reactive power (KVAR) around 5.05\%, which is quite useful for power system networks. In the future, improve the THD and reactive power of Hybrid-APF by using Artificial-Neuro- Fuzzy Logic Controller as a current compensation method.

\section{REFERENECS}

Ahsan, M. K., Pan, T., \& Li, Z. (2018). A Three Decades of Marvellous Significant Review of Power Quality Events Regarding Detection \& Classification. Fournal of Power and Energy Engineering, 6(8), 1-37. https://www.scirp.org/journal/paperinformation. aspx?paperid $=86408$ 
Babu, P. N., Kar, B., \& Halder, B. (2016). Modelling and analysis of a hybrid active power filter for power quality improvement using hysteresis current control technique. In 2016 7th India International Conference on Power Electronics (IICPE) (pp. 1-6). IEEE. https://ieeexplore.ieee.org/document/8079381

Balasubramanian, R., \& Palani, S. (2016). Simulation and performance evaluation of shunt hybrid power filter for power quality improvement using PQ theory. International Journal of Electrical and Computer Engineering, 6(6), 2603. http://ijece.iaescore.com/ index.php/IJECE/article/view/5871

Chau, M. T. (2016). Adaptive current control method for hybrid active power filter. Fournal of Electrical Engineering, 67(5), 343-350. https://www.sciendo.com/article/10.1515/ jee-2016-0049

Damodhar, T. B., \& Kumar, A. S. (2016). Implementation of FPGA based hybrid power generator for PV and wind grid applications. Circuits and Systems, 7(13), 4280-4290. https://www.scirp.org/journal/paperinformation.aspx?paperid=72395

Das, S. R., Ray, P. K., \& Mohanty, A. (2017). Improvement in power quality using hybrid power filters based on RLS algorithm. Energy Procedia, 138, 723-728. https:// doi.org/10.1016/j.egypro.2017.10.207

Demirdelen, T., Inci, M., Bayindir, K. Ç., \& Tümay, M. (2013). Review of hybrid active power filter topologies and controllers. In 4th International Conference on Power Engineering, Energy and Electrical Drives (pp. 587-592). IEEE. https://ieeexplore.ieee. $\mathrm{org} /$ document/6635674

Dhineshkumar, K., \& Subramani, G. (2018). Kalman filter algorithm for mitigation of power system harmonics. International Fournal of Electrical and Computer Engineering, 8(2), 771. http://ijece.iaescore.com/index.php/IJEGE/article/view/10653

Diab, M., El-Habrouk, M., Abdelhamid, T. H., \& Deghedie, S. (2018). Survey of active power filters configurations. In 2018 IEEE International Conference on System, Computation, Automation and Networking (ICSCA) (pp. 1-14). IEEE. https://www. 
semanticscholar.org/paper/Survey-of-Active-Power-Filters-Configurations-DiabEl-Habrouk/3c4052421432706db6368ffd19f3503436b921ff

Esfahani, M. T., Hosseinian, S. H., \& Vahidi, B. (2015). A new optimal approach for improvement of active power filter using FPSO for enhancing power quality. International Fournal of Electrical Power \& Energy Systems, 69, 188-199. https://doi. org/10.1016/j.ijepes.2014.12.078

Kar, B., \& Halder, B. (2016). Comparative analysis of a Hybrid active power filter for power quality improvement using different compensation techniques. In 2016 International Conference on Recent Advances and Innovations in Engineering (ICRAIE) (pp. 1-6). IEEE. https:/ / www.semanticscholar.org/paper/Comparative-analysis-of-a-Hybridactive-power-for-N.-Kar/f8f82e85714345a4c27938421 1e4e6da3ff427d0

Kedra, B. (2014). Comparison of an active and hybrid power filter devices. In 2014 16th International Conference on Harmonics and Quality of Power (ICHQP) (pp. 556-560). IEEE. https://www.semanticscholar.org/paper/Comparison-of-an-active-and-hybridpower-filter-K\%C4\%99dra/ba7b6bc0d0c5a58e73696e0e95e8c87a83147b25

Nandankar, M. P., \& More, D. S. (2017). Performance analysis of transformer-less hybrid active power filter using different inverter topologies. In 2017 International Conference on Intelligent Computing, Instrumentation and Control Technologies (ICICICT) (pp. 892-897). IEEE. https://www.semanticscholar.org/paper/Performance-analysis-of-transformer-lesshybrid-Nandankar-More/f1bda36700e093bbc1c9a5e87fa1f615d8ec093f

Rahmani, S., Hamadi, A., Al-Haddad, K., \& Dessaint, L. A. (2013). A combination of shunt hybrid power filter and thyristor-controlled reactor for power quality. IEEE Transactions on Industrial Electronics, 61(5), 2152-2164. https://ieeexplore.ieee.org/ document/6557048

Schwanz, D., Bollen, M., \& Larsson, A. (2016). A review of solutions for harmonic mitigation. In 2016 17th International Conference on Harmonics and Quality of Power (ICHQP) (pp. 30-35). IEEE. http://www.diva-portal.org/smash/record. jsf?pid=diva2\%3A1047315\&dswid $=-1367$ 
Tahmid, R., \& Ahmad, S. (2017). Power quality improvement by using shunt hybrid active power filter. In 2017 International Conference on Electrical, Computer and Communication Engineering (ECCE) (pp. 381-386). IEEE. https://www.semanticscholar.org/paper/ Power-quality-improvement-by-using-shunt-hybrid-Tahmid-Ahmad/83bb3a469ea 95e3bbb12197e34e67c65453f942a

Temerbaev, S. A., \& Dovgun, V. P. (2014). Improvement of power quality in distributed generation systems using hybrid power filters. In 2014 16th International Conference on Harmonics and Quality of Power (ICHQP) (pp. 694-698). IEEE. https://www.energiaeuropa.com/wp-content/uploads/2020/08/Grasso_Improving_Efficiency_ final_05.pdf

Thuyen, C. M. (2018). Improved p-q harmonic detection method for hybrid active power filter. International Fournal of Electrical and Computer Engineering (IFECE), 8(5), 2910-2919. http://ijece.iaescore.com/index.php/IJEGE/article/view/7800

Thuyen, C. M. (2019). A new design algorithm for hybrid active power filter. International Journal of Electrical $\&$ Computer Engineering, 9(6), 2088-8708. http://ijece.iaescore. com/index.php/IJEGE/article/view/18581

Unnikrishnan, A. K., Ghandira, E., Subash, T. G., Manju, A. S., \& Joseph, A. (2015). Shunt hybrid active power filter for harmonic mitigation: A practical design approach. Sadhana, 40(4), 1257-1272. https://www.ias.ac.in/describe/article/ sadh/040/04/1257-1272

Wang, L., Lam, G. S., \& Wong, M. G. (2018). The Analysis of DC-link Voltage, Compensation Range, Cost, Reliability and Power Loss for Shunt (Hybrid) Active Power Filters. In 2018 IEEE PES Asia-Pacific Power and Energy Engineering Conference (APPEEC) (pp. 640-645). IEEE. https:/ /ieeexplore.ieee.org/document/8566367

Wang, Y. W., Wong, M. C., \& Lam, C. S. (2015). Historical review of parallel hybrid active power filter for power quality improvement. In TENCON 2015-2015 IEEE Region 10 Conference (pp. 1-6). IEEE. https://ieeexplore.ieee.org/document/7373190 
